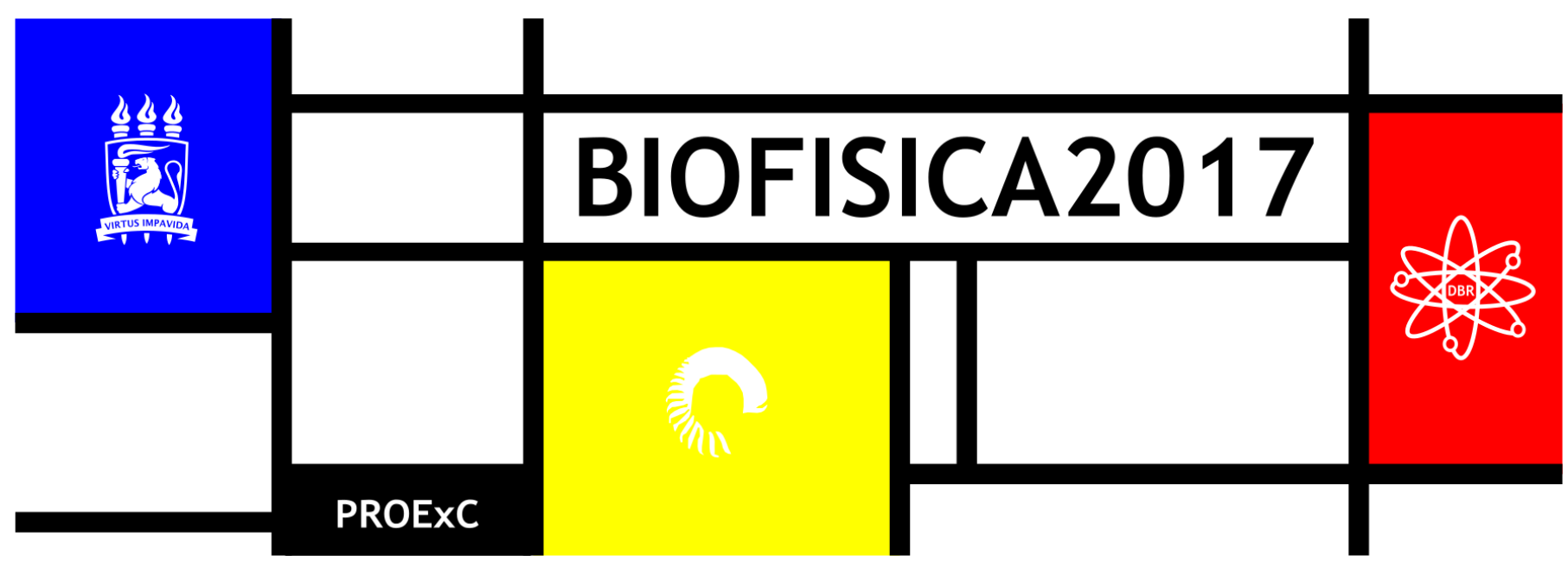

\title{
A IMPORTÂNCIA DA EXPERIMENTAÇÃO NO ENSINO DE CIÊNCIAS: UMA ANÁLISE DE CONCEPÇÕES DOCENTES
}

\author{
Luzia Abílio da Silva ${ }^{1,2, *}$, Raiza Pereira santos de Lucena ${ }^{1,3}$, Karla Maria Euzebio da Silva ${ }^{4}$.
}

\begin{abstract}
'Licenciando(a) do curso de Ciências Biológicas, Universidade Federal de Pernambuco (UFPE); ${ }^{2}$ Laboratório de Biofísica Química- LBQ/UFPE;
${ }^{3}$ Laboratório Biodispositivos Nanoestruturados-BioNano/UFPE, ${ }^{4}$ Docente de Ciências Naturais da Prefeitura do Recife.
\end{abstract} *luzia.abilio@hotmail.com

\section{INTRODUÇÃO}

0 ensino por investigação é extremamente importante para um planejamento em sala de aula fazendo com que o aluno possa aprimorar conhecimento cientifico de forma prática e didática. Para tanto, de acordo com Giordan (1999), que discute o papel da experimentação na construção do conhecimento científico e sua relevância no processo de ensino e aprendizagem, é necessário que os docentes obtenham um conhecimento prévio sobre os conceitos dos alunos no assunto abordado, ou que busquem conhecer esses conceitos para realizar este trabalho em sala de aula, fortalecendo a relação entre aluno e professor e instigando a curiosidade dos estudantes.

Carvalho (2013) discute sobre as atividades realizadas em sala de aula, a comunicação de aluno e professor, e como se planejar para fazer com que aquela aula seja bem mais interessante para o aprimoramento do aluno e aprendizagem sobre o conteúdo. Azevedo (2003) enfatiza a importância do ensino de investigação para a construção do conhecimento científico. Marandino et al.(2009) também discutem a importância das aulas práticas para o ensino de Ciências Naturais e Biologia e como o professor pode lidar com as dificuldades escolares.

Diante do exposto, acreditamos que para a inserção da investigação e experimentação na escola básica, há a necessidade de apropriação dos docentes de seus significados. Assim, durante a disciplina de "Metodologia de Ensino a Biologia 2" , na graduação em Licenciatura em Ciências Biológicas - UFPE realizamos entrevistas com o objetivo de conhecer o trabalho em sala de aula sobre o ensino por investigação e experimentação e obtemos resultados relacionado a essa observação, como opiniões dos profissionais entrevistados e seus métodos didáticos em sala de aula.

\section{METODOLOGIA}

Para o resgate das concepções docentes, realizamos visitas e entrevistas em escolas públicas e privadas com três professores do Ensino de Ciências e Biologia: uma do Fundamental 1, um do Fundamental 2 e uma Ensino Médio. Durante as entrevistas, foram respondidas as seguintes questões: Quais os métodos de ensino e avaliação utilizados em sala de aula para o ensino de ciências ou Biologia?; Em suas aulas ocorre algum tipo de experimentação, que possa esclarecer a teoria realizada antes da aula, na classe?; Quais as condições da escola para realização dos experimentos?; Para você como profissional o que é fundamental para o aprimoramento de ensino e fixação do conhecimento?

Os profissionais entrevistados foram professores, que lecionam tanto no ensino fundamental como no ensino médio, alguns são pedagogos e outros biólogos licenciados que possuem uma grande experiência profissional na área de educação. Estes professores contribuíram para nossa entrevista demostrando um pouco do seu dia á dia e suas dificuldades em sala de aula para aplicar métodos de ensino e aprendizagem.

\section{RESULTADOS E DISCUSSÃO}

De acordo com as entrevistas realizadas obtemos respostas e opiniões diferentes dos profissionais entrevistados. Na primeira pergunta observamos que tanto o Ensino Fundamental como o Médio, tem diversas atividades realizadas em salas de aula que são de acordo com a faixa etária e material didático específico para cada ano letivo. Os professores entrevistados, explicaram um pouco dos seus métodos e avaliações utilizados, com aulas que possa aprimorar o conhecimento e fixar o aprendizado facilitando assim as formas de fazer as avaliações.

Com a segunda pergunta observamos que no Fundamental I a professora não procurou realizar experimentos em sala de aula. Informou que as atividades realizadas são para o aprimoramento comportamental da criança como aprender a ler, escrever e outros aprendizados importantes para sua fase inicial do conhecimento e aprimoramento escolar. No Fundamental II e Ensino Médio os docentes relataram que práticas e experimentos realizados esclarecem algumas teorias sobre o conhecimento cientifico. No entanto, a experimentação não é tão presente em aulas práticas dos docentes.

A esse respeito, de acordo com Marandino et al. (2009): “Para entender as dificuldades de integração das atividades experimentais aos procedimentos rotineiros das aulas de Ciências e Biologia, precisamos reconhecer que, ao lado do funcionamento 
estrutural das escolas, existem elementos associados ás tradições de ensino da escolaridade brasileira que não romperam completamente com uma cultura enciclopédica".

Com a terceira pergunta procuramos saber um pouco sobre a escola e suas condições necessárias para a realização desse tipo de aula, as informações recebidas foram que algumas escolas possuem materiais ou laboratórios disponíveis, mas com equipamentos incompletos que dificulta a elaboração desse tipo de ensino.

Essa dificuldade escolar é um fato histórico da educação brasileira, algo que dificulta a atuação do professor para esse tipo de ensino por experimentação e investigação e é discutida no trabalho de Marandino et al. (2009) que propõem alternativas a ausência de materiais. A última pergunta foi realizada para buscar a opinião dos professores a respeito do aprimoramento ensino e fixação do conhecimento e cada professor teve um modo diferente de responder, no entanto, enfatizaram adaptação de acordo com os vestibulares e mercado de trabalho, mas não aprofundaram a questão.

\section{CONSIDERAÇÕES FINAIS}

Mediante as respostas obtidas, foi possível observar que, embora os professores tenham afirmado a importância das atividades de experimentação, que proporciona melhor compreensão textual, comprovações das teorias, observações, vantagens no aprendizado de ciência, como ampliação dos conhecimentos prévios e oportunidade para reflexões dos alunos, poucos ainda fazem uso dessa modalidade didática.

A maneira que os professores desenvolvem sua experimentação em sala de aula e com bases nos texto abordados no artigo, podemos observar a importância que o ensino por experimentação tem de facilitar o aprimoramento do conhecimento cientifico, e que muitos professores não utilizam esse método didático, muitas vezes por falta de estrutura ou laboratório, de materiais, equipamentos e tempo para realizar a experimentação. Foi possível observar, de forma geral, a falta de interesse de alguns profissionais da educação em utiliza experimentação em sala de aula, pois a maioria prioriza a memorização dos conteúdos. Acreditamos que é necessária uma maior utilização da experimentação, que auxiliam na construção do conhecimento cientifico por ser um instrumento essencial para o aprimoramento de reflexões e investigações.

\section{REFERÊNCIAS}

AZEVEDO, M. C.P. S. Ensino por investigação: problematizando as atividades em sala de aula. In: CARVALHO, A.M.P.. Ensino de Ciências: unindo a pesquisa e a prática. São Paulo: Pioneira Thomson, 2003.

CARVALHO, A. M. P. (Org.). Ensino de Ciências por Investigação: condições para implementação em sala de aula. São Paulo: CENGAGE Learning, 2013.

GIORDAN, M. O papel da experimentação no ensino de ciências, Química Nova na Escola - Experimentação e Ensino de Ciências $\mathrm{n}^{\circ}$ 10, novembro 1999.

MARANDINO, M., SELLES, S. E., FERREIRA, M. S. Ensino de Biologia: histórias e práticas em diferentes espaços educativos. São Paulo: Cortez, 2009. 